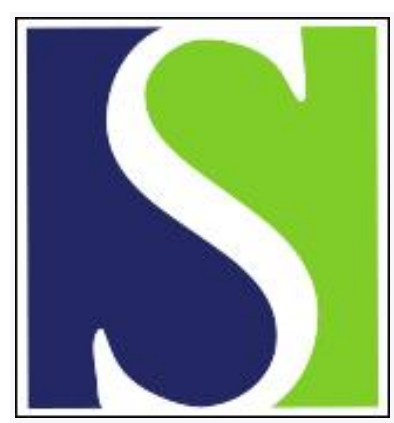

Scand J Work Environ Health 1984;10(2):115-119

https://doi.org/10.5271/sjweh.2356

Issue date: Apr 1984

Airborne molds and actinomycetes in the work environment of farmer's lung patients in Finland.

by Kotimaa $\mathrm{MH}$, Husman $\mathrm{KH}$, Terho EO, Mustonen $\mathrm{MH}$

This article in PubMed: www.ncbi.nlm.nih.gov/pubmed/6382592

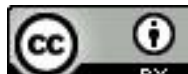




\title{
Airborne molds and actinomycetes in the work environment of farmer's lung patients in Finland
}

\author{
by Marjut $\mathrm{H}$ Kotimaa, BA, ${ }^{1}$ Kaj $\mathrm{H}$ Husman, MD, MSc, ${ }^{1}$ Erkki O Terho, $\mathrm{MD},{ }^{2}$ Mirja H Mustonen, $\mathrm{BA}^{3}$
}

\begin{abstract}
KOTIMAA MH, HUSMAN KH, TERHO EO, MUSTONEN MH. Airborne molds and actinomycetes in the work environment of farmer's lung patients in Finland. Scand J Work Environ Health 10 (1984) 115-119. Occurrence of molds and actinomycetes in the breathing zone of farmers during the handling of hay, straw, or grain was studied with the use of an Andersen sampler on 35 farms in Finland. On 24 farms there was a person with recently diagnosed farmer's lung disease, and on 11 farms people were free of the disease. The total spore concentration and the concentrations of the spores of Thermoactinomyces $(T)$ vulgaris, Micropolyspora $(M)$ faeni, and Aspergillus $(A)$ umbrosus were statistically significantly higher on the farms of patients with farmer's lung than on the disease-free farms. The mean proportions of the spores of thermotolerant and thermophilic microbes were greater on the farms of farmer's lung patients than on the reference farms. $T$ vulgaris was the predominant actinomycete species. Both $T$ vulgaris and $A$ umbrosus were found on all farms of farmer's lung patients, but $M$ faeni on only about half of such farms. The findings match the results of previous microbiological analyses of Finnish moldy hay and serological analyses of Finnish farmer's lung patients. It seems that $T$ vulgaris, not $M$ faeni, may be the main causative agent of farmer's lung in Finland. The possible etiologic role of $A$ umbrosus requires further investigation. Because the farmers often failed to identify the moldiness of the plant material in contrast to researchers, it might be possible, through training, to improve farmers' ability to identify moldiness.
\end{abstract}

Key terms: agriculture, allergic alveolitis, Andersen sampler, biological dust, spore concentration.

Farmer's lung disease is a form of extrinsic allergic alveolitis resulting from recurrent exposure to moldy plant materials (8). British studies have shown that a thermophilic actinomycete, Micropolyspora (M) faeni, is the main causative agent of farmer's lung $(9,10)$. The microflora of Finnish moldy hay differs from that of British moldy hay $(12,13)$; thus it can be assumed that also the microorganisms liberated in the ambient air causing farmer's lung might be different. We investigated the spore dust exposure of farmers with clinically established farmer's lung disease and that of healthy farmers in order to obtain information on the possible etiologic factors of the disease in Finland.

\section{Material and methods}

The samples for the microbial analyses were collected on the farms of 27 patients with recently diagnosed farmer's lung. Data for three of the farms had to be excluded from the final statistical analyses, however, because the hay having originally caused the farmer's

1 Kuopio Regional Institute of Occupational Health, SF-70101 Kuopio, Finland.

2 Department of Pulmonary Diseases, Kuopio University Central Hospital, SF-71880 Tarinaharju, Finland.

3 Valio, The Finnish Co-Operative Dairies' Association/University of Kuopio, SF-70211 Kuopio, Finland.

Reprint requests to: Ms M Kotimaa, Kuopio Regional Institute of Occupational Health, PO Box 261, SF-70101 Kuopio, Finland. symptoms had been discarded and replaced by purchased hay with a better quality. Thus there were 24 farms of farmer's lung patients in the final analyses.

Eleven farms of the patients' healthy siblings living roughly in the same geographic area were used as reference farms. Siblings were chosen because we wanted to ensure that the farmers on the reference farms were healthy for environmental rather than genetic reasons.

Spore concentrations were measured as soon as possible after the disease had been diagnosed. In practice the time between the diagnosis and the microbial measurements was about two weeks. Measurements on the reference farms were made at roughly the same time. During the spore measurements the plant material (hay, grain, or straw) lately used on the farms was handled in an ordinary manner in the cowshed. A six-stage Andersen sampler (model 10-800 Andersen 2000 Inc, the United States) was used to examine the microflora liberated from moldy material (1); such microflora is thought to be indicative of the extent of molding.

The culture media, incubation temperatures, and incubation times are presented in table 1 . The sampling time was adjusted to avoid overloading of the agar plates, depending on the visible moldiness of the material, and it varied from 5 to $30 \mathrm{~s}$. Air was sampled as near the worker's breathing zone as possible; this procedure enabled the estimation of the worker's actual exposure to spores. 
Table 1. The culture media, incubation temperatures, and incubation times used in the Andersen samplings.

\begin{tabular}{|c|c|c|c|c|}
\hline Microorganism & Medium & Reference & $\begin{array}{l}\text { Incubation } \\
\text { temperature } \\
\left({ }^{\circ} \mathrm{C}\right)\end{array}$ & $\begin{array}{l}\text { Duration of } \\
\text { incubation } \\
\text { (d) }\end{array}$ \\
\hline $\begin{array}{l}\text { Aspergillus umbrosus } \\
\text { Other mesophilic molds } \\
\text { Thermotolerant molds } \\
\text { Thermophilic actinomycetes }\end{array}$ & $\begin{array}{l}\text { Sodium chloride-malt extract agar } \\
\text { Hagen-agar } \\
\text { Hagen-agar } \\
\text { Half-strength nutrient agar }\end{array}$ & $\begin{array}{l}\text { Terho (12) } \\
\text { Russel (11) } \\
\text { Russel (11) } \\
\text { Corbaz et al (2) }\end{array}$ & $\begin{array}{l}20 \\
20 \\
40 \\
55\end{array}$ & $\begin{array}{c}7 \\
7 \\
4 \\
2-3\end{array}$ \\
\hline
\end{tabular}

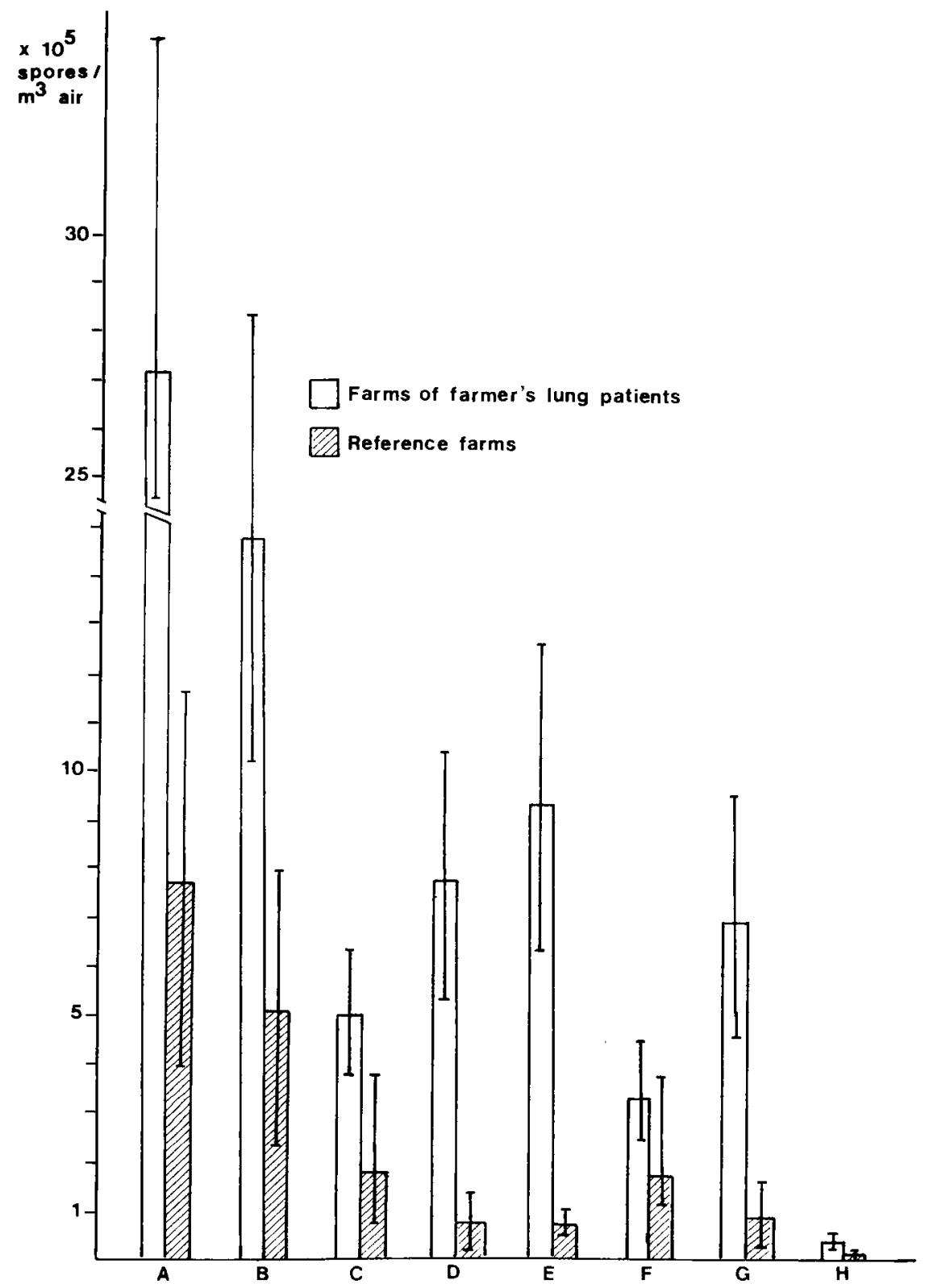

Figure 1. The mean spore concentrations of different types of microorganisms on the farms of the farmer's lung patients and on the reference farms. $(A=$ total spore concentration, $B=$ mesophilic molds, $C=$ thermotolerant molds, $D=$ thermophilic acinomycetes, $\mathrm{E}=$ Aspergillus umbrosus, $\mathrm{F}=$ Aspergillus fumigatus, $\mathrm{G}=$ Thermoactinomyces vulgaris, $\mathrm{H}=$ Micropolyspora faeni) 
In addition both the researchers and the farmers visually estimated the moldiness of the same material.

A questionnaire was used to ascertain the weather conditions during the previous growing season and the haymaking methods used on the farms.

The differences in the mean concentrations of spores on the two types of farms were tested statistically by Student's t-test.

\section{Results}

The total spore concentrations and the spore concentrations of different types of microorganisms on both types of farms are shown in figure 1 .

The mean total spore concentration on the farms of the farmer's lung patients (range 0.04-13.7 $\cdot 10^{6}$ spores $/ \mathrm{m}^{3}$ of air) was statistically significantly higher ( $p<0.01$ ) than on the reference farms (range $0.02-3.6 \cdot 10^{6}$ spores $/ \mathrm{m}^{3}$ of air) (figure 1 ). The $\mathrm{mi}$ crobial analyses of the three farms on which moldy hay had been replaced by purchased hay, and which have not been included, showed the lowest spore concentrations, equal to those of the reference farms. As for the different types of microorganisms, the mean concentrations of the spores of mesophilic molds (p $<0.01$ ) and thermophilic actinomycetes $(\mathrm{p}<$ 0.01 ) were statistically significantly greater on the patients' farms than on the reference farms. The difference in the amount of spores of thermotolerant molds was parallel ( $\mathrm{p}<0.10$ ), but not statistically significant.

Of individual species, the spores of Aspergillus ( $A$ ) umbrosus ( $\mathrm{p}<0.01$ ) (included in mesophilic molds) and those of Thermoactinomyces $(T)$ vulgaris $(\mathrm{p}<0.05)$ and Micropolyspora $(M)$ faeni $(\mathrm{p}<0.05)$ (both included as thermophilic actinomycetes) were statistically significantly more numerous on the patients' farms than on the reference farms.

For the spores of $A$ fumigatus (included in thermotolerant molds) there was no statistically significant difference between the two types of farms.

The proportions of the spores of different microbe groups found on the farms of the farmer's lung patients differed slightly from those found on the reference farms. On the former type of farms, the mean spore percentage was 62 for mesophilic molds, 19 for thermotolerant molds, and 19 for thermophilic actinomycetes. On the reference farms, the corresponding percentages were 86,6 , and 8 , respectively.

Table 2 shows on how many farms each microorganism or group of microorganisms was found. As regards the individual species, other than those usually connected with farmer's lung, the mesophilic microorganisms Cladosporium and Alternaria and yeasts were more often found on the reference farms than on the farms of the farmer's lung patients. The Aspergillus species, the Rhizopus species, and $A$ niger were more common on the patients' farms, as were the thermotolerant molds Mucor species, $A$ niger, and Paecilomyces species. The thermophilic Streptomyces species was more common on the reference farms than on the farms of the farmer's lung patients. The differences were not, however, statistically significant except for the species Alternaria and Streptomyces.

In the inquiry weather was said to have been more rainy on the patients' farms than on the reference farms during both the growing season of hay and the haymaking time. The baling of hay was more common on the patients' farms. The differences were not however statistically significant.

Table 2. Occurrence of the most common molds and actinomycetes on the farms of the farmer's lung patients $(N=24)$ and on the reference farms $(N=11)$. (NS = not significant)

\begin{tabular}{|c|c|c|c|c|c|}
\hline \multirow{2}{*}{ Microorganism } & \multicolumn{2}{|c|}{$\begin{array}{l}\text { Farms of farmer's } \\
\text { lung patients }\end{array}$} & \multicolumn{2}{|c|}{ Reference farms } & \multirow{2}{*}{$\begin{array}{c}\text { Statistical } \\
\text { significance }\end{array}$} \\
\hline & $\mathrm{N}^{\mathrm{a}}$ & $\%$ & $\mathbf{N}^{\mathrm{a}}$ & $\%$ & \\
\hline
\end{tabular}

\section{Mesophilic molds and yeasts}

Aspergillus umbrosus

Penicillium species

Cladosporium species

Yeasts

Aspergillus species

Rhizopus species

Aspergillus niger

Alternaria species

Thermotolerant molds

Aspergillus fumigatus

Mucor species

Aspergillus niger

Paecilomyces species

Thermophilic actinomycetes

Thermoactinomyces vulgaris

Micropolyspora faeni

Streptomyces species

$\begin{array}{rr}24 & 100 \\ 24 & 100 \\ 15 & 63 \\ 13 & 5 \\ 13 & 54 \\ 9 & 38 \\ 6 & 25 \\ 3 & \end{array}$

100
100
63
54
54
38
25
13

11
11
9
9
3
2
1
5

$\begin{array}{rr}24 & 100 \\ 21 & 8 \\ 10 & 4 \\ 9 & 38\end{array}$

$\begin{array}{rr}11 & 100 \\ 8 & 73 \\ 1 & \\ 2 & 18 \\ & \\ 11 & 100 \\ 5 & 45 \\ 10 & 9\end{array}$

a $N=$ number of farms on which the microorganism was found. 
The farmers often failed to identify the moldiness of the stored plant material. When the border between good and moldy material was determined, on the basis of the microbiological analyses, as 500,000 spores $/ \mathrm{m}^{3}$ of air (below which all samples were classified visually as good by both the researchers and the farmers), the farmers considered $16(64 \%)$ of 25 moldy samples to be good. In contrast only 2 $(8 \%)$ of 25 moldy samples were classified as good by the researchers. The farmers' and researchers' opinions of the quality of the plant material matched the microbiological classification in 54 and $94 \%$ of the cases, respectively. The differences between the microbiological classification and the farmers' classifications, as well as between the researchers' classifications and the farmers' classifications, were statistically significant (McNemar's test, $\mathrm{p}<\mathbf{0 . 0 0 1}$ ).

\section{Discussion}

The total spore concentrations were greater on the farms of the farmer's lung patients than on the reference farms. Mesophilic molds were the predominant group on nearly all farms, but the proportions of spores originating from thermotolerant and thermophilic microorganisms were greater on the farms of the patients than on the reference farms. This finding indicates that the plant material (hay, grain, or straw) was moldier and the temperature of the material due to molding higher on the farms of the patients. From the group of mesophilic molds, especially the spores of the $A$ glaucus group fungus $A$ umbrosus were more numerous on the farms of patients than on the reference farms, this finding also indicates that hay was more moldy on the patients' farms (5).

Gregory et al (5) have reported that the water content of hay greatly influences the microflora of hay during storage. Thermotolerant molds, such as the Mucor species, A niger, and the Paecilomyces species, were found slightly more often on the farms of the patients than on the reference farms. This finding indicates that the initial water content of the material had apparently been greater and molding had proceeded further on the patients' farms. The Paecilomyces species, which was more common on the patients' farms, is one of the last mold species to appear when heating occurs in hay (5). The greater initial water content of hay can be explained by the environmental conditions on the farms, ie, it was said to have been more rainy during the growing season and the haymaking time on the patients' farms.

Gregory \& Lacey (4) have proposed a classification of the quality of hay according to certain indicator microorganisms liberated from hay. According to this classification, there was hay belonging to the group including moldy hay or hay conducive to farmer's lung more frequently than was expected on the patients' farms $\left(\chi^{2}=11.6, \mathrm{p}<0.01\right)$. According to the view that causative agents of farmer's lung belong to the groups of thermotolerant molds or thermophilic actinomycetes $(3,4,5,10,14)$, it can be concluded that the farmers on most of the farms of farmer's lung patients have a greater risk of contracting allergic alveolitis than those working on the reference farms.

Typical of the aerospora of the reference farms was the occurrence of spores of so-called field fungi (6), ie, the species Cladosporium and Alternaria, together with small amounts of spores of some thermotolerant molds and thermophilic actinomycetes. According to British studies (5) this kind of microflora is characteristic of "good hay." The thermophilic Streptomyces species was more abundant on the reference farms than on the farms of the patients. In the samples collected from patients' farms the Streptomyces species may have been overgrown however by $T$ vulgaris, the spores of which were much more numerous on the patients' farms, because, according to Corbaz et al (2), the amounts of both $T$ vulgaris and the thermophilic Streptomycetes species are greater in hay conducive to farmer's lung than in good hay.

$T$ vulgaris but not $M$ faeni was the predominant actinomycete in the spore dust of the farms of the farmer's lung patients. $M$ faeni was found only on about half of such farms, although in some specimens the growth of $M$ faeni may have been inhibited by the abundant growth of $T$ vulgaris. Spore concentrations of the mesophilic fungus $A$ umbrosus were even higher on the patients' farms and differed statistically more significantly from the spore concentrations found on the reference farms. This phenomenon is in sharp contrast with the earlier British findings (14) but matches with previous analyses of Finnish moldy hay $(12,13)$ and with serological findings of Finnish farmer's lung patients $(7,12,13)$. It seems possible that $T$ vulgaris may be the main causative agent of farmer's lung in Finland. The possible role of $A \mathrm{um}$ brosus in the production of the disease requires further investigation.

Finally, it is worthwhile emphasizing that in $64 \%$ of the cases the farmers failed to identify the moldiness of the plant material. As the researchers failed in only $8 \%$ of the cases, it might be possible to improve, by training, the farmers' ability to identify the moldiness of the plant material.

\section{Acknowledgments}

We thank Ms M Korhonen for her technical assistance and the people on the farms for their cooperation.

This work was financially supported by the Farmer's Pension Institute of Finland and the Academy of Finland.

\section{References}

1. Andersen AA. New sampler for the collection, sizing and enumeration of viable airborne particles. $J$ Bacteriol 76 (1958) $471-484$. 
2. Corbaz R, Gregory PH, Lacey ME. Thermophilic and mesophilic actinomycetes in mouldy hay. J Gen Microbiol 32 (1963) 449-455.

3. Festenstein GN, Lacey J, Skinner FA, Jenkins PA, Pepys J. Self-heating of hay and grain in Dewar flasks and the development of farmer's lung antigens. J Gen Microbiol 41 (1965) 389-407.

4. Gregory PH, Lacey ME. Mycological examination of dust from mouldy hay associated with farmer's lung disease. J Gen Microbiol 30 (1963) 75-88.

5. Gregory PH, Lacey ME, Festenstein GN, Skinner FA. Microbial and biochemical changes during the moulding of hay. J Gen Microbiol 33 (1963) 147-174.

6. Hudson HJ. Fungal saprophytism. Edward Arnold, London 1972.

7. Katila M-L, Mäntyjärvi RA. The diagnostic value of antibodies to the traditional antigens of farmer's lung in Finland. Clin Allergy 8 (1978) 581-587.

8. Pepys J. Hypersensitivity diseases of the lungs due to fungi and organic dusts. In: Kanos P, Hasck M, Inderleitzin TM, Miescher PA, Waksman BH, ed. Monographs in allergy. Volume 4. S Karger, Basel 1969.

9. Pepys J, Jenkiiis PA. Precipitin (F.L.H.) test in farm- er's lung. Thorax 20 (1965) $21-35$.

10. Pepys J, Jenkins PA. Festenstein GN, Gregory PH, Lacey ME, Skinner FA. Farmer's lung: Thermophilic actinomycetes as a source of 'farmer's lung hay' antigen. Lancet 2 (1963) 607-611.

11. Russel BS. Mycology guidebook. Mycology guidebook Committee, Mycological Society of America, University of Washington Press, Seattle and London 1974.

12. Terho EO. Microbiological and serological studies on farmer's lung disease. University of Kuopio, Kuopio 1978. (Publications of the University of Kuopio, Medicine, Series Original Reports 1/1978).

13. Terho EO, Lacey J. Microbiological and serological studies of farmer's lung in Finland. Clin Allergy 9 (1979) 43-52.

14. Wardrop VE, Blyth W, Grant WB. Farmer's lung in a group of Scottish dairy farms. Br J Ind Med 34 (1977) $186-195$.

Received for publication: 11 October 1983 